\title{
Computational Exploration of Dibenzo [a,l] Pyrene Interaction to DNA and its Bases: Possible Implications to Human Health
}

\author{
Khan Mohammad Kalim Ahmad ${ }^{1}$ (D), Akhtar Salman ${ }^{1}$ (D), Al-Khodairy Salman F 2 (D), Al-Marshad Feras \\ $M^{3}$ (D), Alshahrani Abdulrahman M. ${ }^{3}$ (D), Arif Jamal M 6** (D) \\ 1 Department of Bioengineering, Integral University, Lucknow-226026, Uttar Pradesh, India; mkakhan@iul.ac.in \\ (K.M.K.A.); sakhtar@iul.ac.in (A.S.); \\ 2 Imam Muhammad Ibn Saud Islamic University, Riyadh 13318, KSA; sfalkhodiry@ sm.imamu.edu.sa (A.K.S.F.); \\ 3 Department of Internal Medicine, College of Medicine, Shaqra University, Shaqra, 11961, KSA; falmarshad@ su.edu.sa \\ (A.M.F.M.); alshahrani.md@ su.edu.sa (A.A.M.); \\ 4 Department of Biochemistry, College of Medicine, Shaqra University, Shaqra, 11961, KSA; jmarif@ su.edu.sa (A.J.M.); \\ * Correspondence: jmarif@su.edu.sa;
}

Scopus Author ID 6603906517

Received: 6.11.2020; Revised: 2.12.2020; Accepted: 5.12.2020; Published: 10.12.2020

\begin{abstract}
Dibenzo[a,l]pyrene (DBP), an environmental pollutant, undergoes a series of enzymatic reactions yielding electrophilic diastereomeric diol-epoxides (DEs) that subsequently bind to DNA covalently and hampers the healing mechanism of cascaded biological pathways resulting in onset of different diseases. In the proposed work, we meticulously investigated and elucidated the mechanistic details of DNA adduct formation and nucleotide excision repair (NER) pathway proteins interaction with all possible diastereomers of dibenzo[a,l]pyrene-diol-epoxides (DBPDEs) namely- $( \pm)$-anti-, $( \pm)$ syn-, trans- and cis- forms of (-)-anti- and (+)-syn- DBPDEs through a computational simulation study. Our findings revealed that ( \pm )-anti- and (-)-syn-DBPDEs interact more strongly with dT20 while (+)syn-DBPDE exhibits strong interaction with dG6. Moreover, cis- and trans-conformations of (-)-antiand (+)-syn-DBPDEs depicted strong binding towards $\mathrm{N}^{6}$-dA. Furthermore, aforesaid metabolic intermediates exhibited weak interactions with NER proteins. This imbalance of interaction tendencies relatively favors the DNA-adduct formation than the NER pathway. Based on our computational data, a robust understanding of the underlying molecular mechanism(s) of DBP-DNA interactions may subsequently lead to the design of novel potential compounds to exert inhibition and block its DNA binding ability and eventually facilitate cancer prevention.
\end{abstract}

Keywords: dibenzo[a,l]pyrene; environmental pollutant; molecular docking; DNA adduct; NERproteins.

(C) 2020 by the authors. This article is an open-access article distributed under the terms and conditions of the Creative Commons Attribution (CC BY) license (https://creativecommons.org/licenses/by/4.0/).

\section{Introduction}

Dibenzo[a,l]pyrene (DBP), a well-studied environmental polycyclic aromatic hydrocarbon $(\mathrm{PAH})$ and smoke carcinogen, is mainly produced by incomplete combustion of woods, charcoals, and fossil fuels [1-4]. Biotransformation of DBP into its carcinogenic diolepoxides (DEs) is facilitated by a series of catalytic reactions [5-8]. PAH diol-epoxides can form adducts with DNA, RNA, and proteins, but their mutagenic and tumorigenic effects are thought to be related to the covalent interaction with DNA $[9,10]$. The majority of diol-epoxidederived DNA adducts have been found to result from the reaction of the benzylic oxiranyl 
carbon of the molecule with the exocyclic amino groups of the DNA bases deoxyguanosine (dG) and deoxyadenosine (dA) [9-13]. Research looking at preferences information of DNA adducts shows that bay-region diol-epoxides prefer forming adducts at the exocyclic $\mathrm{N}^{2}$-amino group of $\mathrm{dG}$ whereas the sterically hindered fjord-region diol-epoxides favour reaction with the $\mathrm{N}^{6}$-amino group of dA [14-17], For instance, the bay-region diol-epoxide (+)-antibenzo $[a]$ pyrene-7,8-diol-9,10-epoxide (BPDE) has $>90 \%$ preference of forming DNA adducts with $\mathrm{dG}[6,7]$ whereas fjord region diol-epoxide (-)-anti-dibenzo[ $[a, l]$ pyrene-11,12-diol-13,14epoxide (DBPDE) shows a corresponding 75\% preference for dA adducts [14-17].The difference in DNA binding preference between bay- and fjord-region diol-epoxides is probably due to the structural dissimilarities $[18,19]$.

To handle different DNA adducts or damage that may arise in a cell, versatile, and sophisticated cellular machinery comprised of several different pathways has been developed [20-22]. The two main mechanisms for excision of DNA damage are base excision repair (BER) and nucleotide excision repair (NER). The most apparent function of NER in humans is to remove those photoproducts from DNA caused by UV-irradiation. It is especially apparent in individuals with NER defects, e.g., the disorder Xeroderma pigmentosum (XP), where patients show a high incidence of UV-related skin cancers [23]. However, NER has also been shown to be an effective DNA repair strategy for eliminating a vast number of bulky PAH diolepoxide DNA adducts [24-26]. NER in human cells essentially involves the steps-recognition of DNA damage, incision, and subsequent excision of the DNA strand containing the lesion and, finally, DNA synthesis and ligation [27-30]. The most critical step in NER is the recognition of the DNA lesion, a mechanism principally different in global genome repair (GGR) and transcription-coupled repair (TCR). While the DNA damage binding protein (DDB) and Xeroderma pigmentosum group C (XPC)-human homolog of RAD23B (hHR23B) are responsible for the rate-limiting step in GGR, the arrest of RNA polymerase II upon encountering a DNA adduct during translation initiates the repair in TCR [30,31]. Although the initiation of the two different pathways is different, they both lead to the recruitment of the entire repair protein apparatus, in the latter case, with the Cockayne syndrome proteins CSA and CSB. Subsequently, the lesions are opened by the concerted action of Xeroderma pigmentosum group A (XPA), replication protein A (RPA), and the helicase subunits of the transcription factor IIH (TFIIH) complex. During incision of the damaged DNA, the Xeroderma pigmentosum group F (XPF) intricate cuts at the single-strand to double-strand transition on the 5' side of the damage, and Xeroderma pigmentosum group G (XPG) cuts at the 3' side of the open complex. Finally, DNA excision and de novo synthesis are accomplished by mammalian DNA replication factors such as the heterotrimeric replication protein A (RPA), proliferating cell nuclear antigen (PCNA) and DNA polymerase $\delta$ (DPOL $\delta$ ) and $\varepsilon$ (DPOL $\varepsilon$ ). The reaction is completed by ligation of the newly synthesized DNA [31,32].

In this study, we have comprehensively explored and explicated the mechanism of DNA adduct formation by different diol-epoxides enantiomers of DBP viz., ( \pm )-antiDBPDE, ( \pm -syn-DBPDE, trans- and cis- forms of (-)-anti-DBPDE, and (+)-syn-DBPDE (Figure 1a-h), followed by molecular interaction studies of metabolites above with NERpathway proteins viz., DDB, XPC, hHR23B, TFIIH, XPA, RPA, XPF, DPOL $\delta$, DPOL $\varepsilon$ and PCNA through the integrated approach of computational biology and bioinformatics. 
(a)

(b) (c)

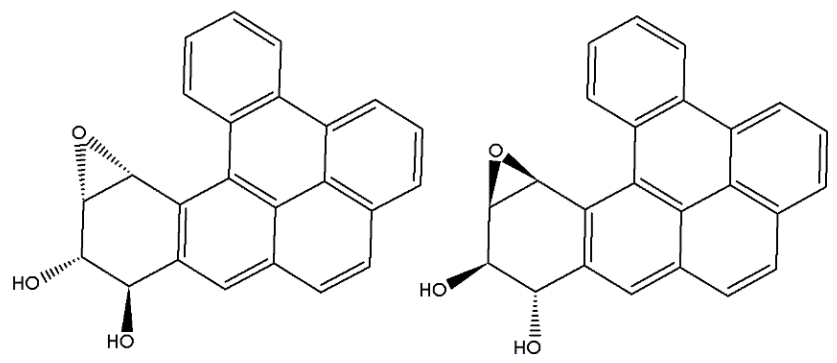<smiles></smiles>

(d)

(e)<smiles></smiles>

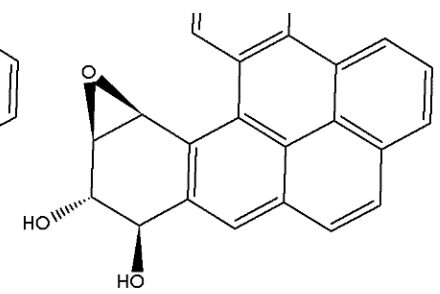

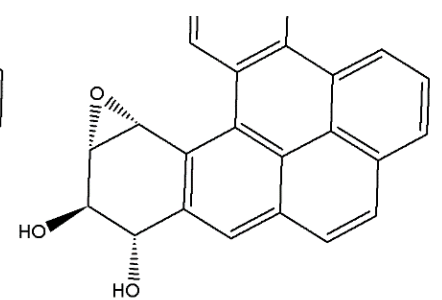

(f)<smiles>c1ccccc1</smiles>

(g)<smiles>C=Cc1ccc2cc3c(c(C)c2c1C)[C@H](C)[C@H](O)[C@H](O)[C@H]3O</smiles><smiles>[C]1C=CC=C1</smiles>

(h)<smiles>Cc1cccc2ccc3cc4c(c(C)c3c12)[C@H](C)[C@@H](O)[C@@H](O)[C@H]4O</smiles>

Figure 1. Chemical structures of (a) (-)-anti-DBPDE; (b) (+)-anti-DBPDE; (c) trans-derivative of (-)-antiDBPDE; (d) cis-derivative of (-)-anti-DBPDE; (e) (-)-syn-DBPDE; (f) (+)-syn-DBPDE; (g) trans-derivative of $(+)$-syn-DBPDE; (h) cis-derivative of (+)-syn-DBPDE.

\section{Materials and Methods}

\subsection{Retrieval and optimization of targets $3 D$ structures.}

The 3D structures of DNA (PDB: 2LZK), DDB (3EI4), XPC (2GGM), hHR23B (1PVE), TFIIH (1PFJ), XPA (1D4U), RPA (1JMC), XPF (2A1J), DPOL $\delta$ (3E0J), DPOL $\varepsilon$ (3MR2) and PCNA (1U7B) were retrieved from Protein Data Bank (http://www.rcsb.org). All targets were prepared for molecular interaction so that undesired atoms, ions, and molecules were removed. The CHARMm force field was assigned to optimize target biomolecules, followed by energy minimization using steepest descent and conjugate gradient algorithms [33].

\subsection{Retrieval and optimization of ligands $3 D$ structures.}

Chemical structures of all diastereomeric-DBPDEs were drawn using ChemDraw tools (www.cambridgesoft.com). The Simplified Molecular-Input Line-Entry System (SMILES) notations were $( \pm)$-anti-, $( \pm)$-syn-, trans- and cis- forms of (-)-anti- and (+)-syn- DBPDE were taken for each of the ligands and by using publically available tool CORINA (http://www.molecular-networks.com/products/corina) generating 3D structure structural suitable for molecular interaction tool viz., AutoDock Tool 4.0 (ADT) [34]. CHARMm force 
field was applied, and subsequent energy minimization was accomplished using the steepest descent algorithm [33].

\subsection{Active site identification.}

We identified the preferable ligand binding site of different proteins of NER pathways by Q-Site finder (http://www.modelling.leeds.ac.uk/qsitefinder). It takes 3-D co-ordinates of biomolecules as reference points. It predicts plausible binding cavities of residues with graphic representations as output [35-37].

\subsection{Computational simulation.}

Computational interaction of DBPDEs and biomacromolecules was carried out using ADT to find the preferred binding orientation. A grid-box within a grid parameter file (gpf) generated was large enough to cover the binding site and accommodate ligands to move freely $[34,38]$. The number of grid points in $\mathrm{x}, \mathrm{y}$, and $\mathrm{z}$-axes was $60 \times 60 \times 60 \AA$. The distance between the two connecting grid points was $0.375 \AA$. The center of the ligand in the X-ray crystal structure was used as the center of the grid-box. Lamarckian Genetic Algorithm (LGA), which has enhanced performance relative to simulated annealing and GA alone were used for receptor-fixed ligand-flexible docking calculations [39]. Ten search attempts were performed for ligands. Before the LGA run, the maximum number of energy evaluations was 2500000. The maximum number of generations of the LGA run before termination was 27000. Other docking parameters were set to the software's default values. During the docking process, a maximum of 10 different conformations was considered. The conformer with the lowest binding free energy of binding $(\Delta \mathrm{G})$ and inhibition constant $(\mathrm{Ki})$ ) was used for further analysis [40-44].

\subsection{Visualization of docked complexes.}

The docked complex of biomolecule and ligands was visualized by Ligplot, Ghost script viewer (GSV), PyMol (http://www.pymol.org), and Discovery studio visualizer [45]. The Ligplot generates a postscript (ps) file, subsequently converted into the desired image by GSV.

\subsection{Validation of docking methodology.}

Ligand present within the PDB structure of DNA (PDB: 2LZK) was extracted and redocked using the same parameters used for docking DBP's diol-epoxides to validate the docking program. The top-ranking conformational clusters from this dock were evaluated in terms of root mean square deviation between docked position and experimentally determined position for the ligand. The low RMS (1.20 $\AA$ ) between the experimental and docked coordinates of ligand indicated the same binding orientation that favored the validation of the adopted docking method $[8,36,37,46,47]$.

\section{Results and Discussion}

\subsection{Diol-epoxides-DNA adduct formation by DBP.}

Our docking results revealed that trans- form of (-)-anti-DBPDE showed strong binding affinity with DNA (BE: $-9.83 \mathrm{kcal} / \mathrm{mol}, \mathrm{Ki}: 0.062 \mu \mathrm{M}$ ) followed by trans- form of (+)-syn- 
DBPDE $(-9.78 \mathrm{kcal} / \mathrm{mol}, 0.069 \mu \mathrm{M})$, cis- form of (-)-anti-DBPDE $(-8.88 \mathrm{kcal} / \mathrm{mol}, 0.308 \mu \mathrm{M})$, cis- form of (+)-syn-DBPDE ( $-8.62 \mathrm{kcal} / \mathrm{mol}, 0.479 \mu \mathrm{M}),(-)$-anti-DBPDE $(-8.49 \mathrm{kcal} / \mathrm{mol}$, $0.599 \mu \mathrm{M}),(+)$-syn-DBPDE $(-8.48 \mathrm{kcal} / \mathrm{mol}, 0.612 \mu \mathrm{M}),(+)$-anti-DBPDE $(-7.50 \mathrm{kcal} / \mathrm{mol}$, $3.21 \mu \mathrm{M})$ and (-)-syn-DBPDE $(-7.20 \mathrm{kcal} / \mathrm{mol}, 5.24 \mu \mathrm{M})$.

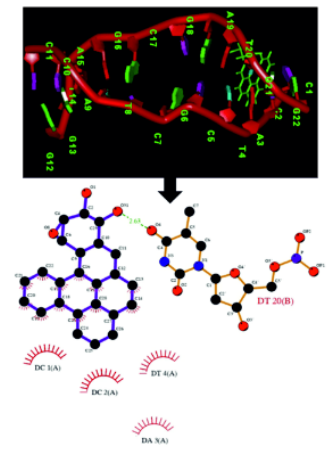

(a)

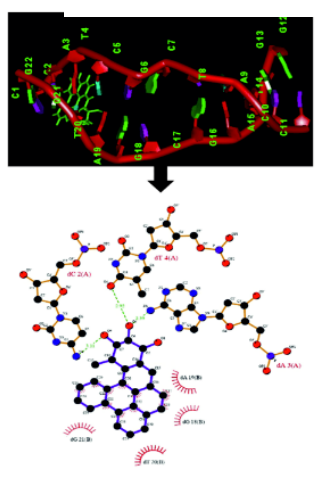

(e)

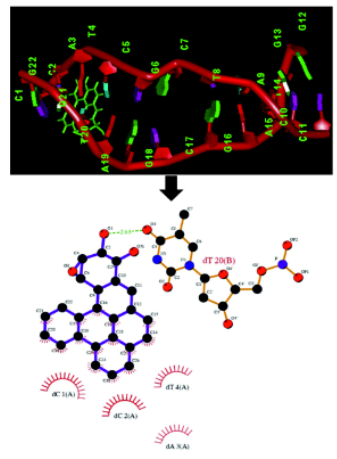

(b)

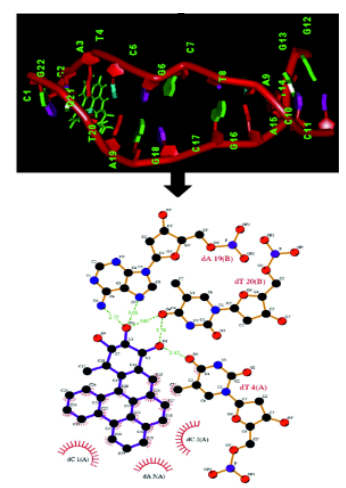

(f)

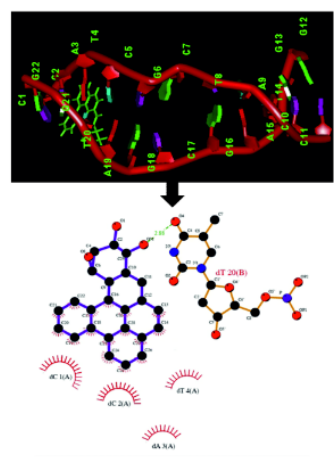

(c)

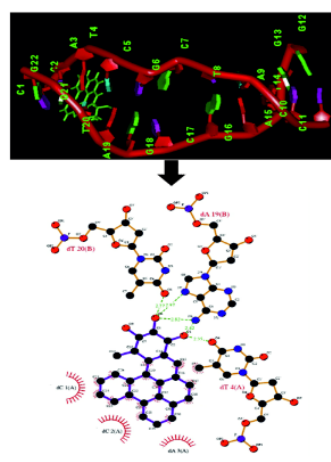

(g)

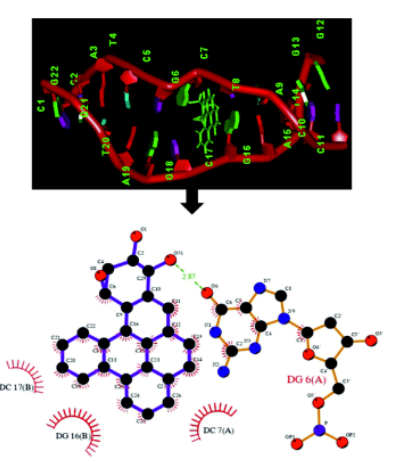

(d)

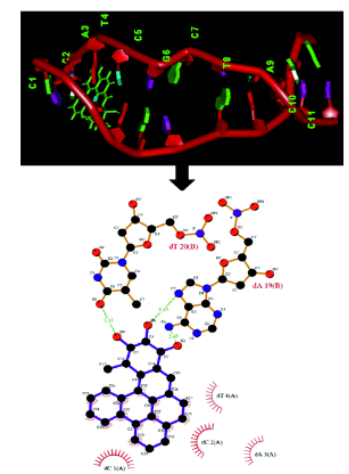

(h)

Figure 2. Molecular interactions of DNA with (a) (-)-anti-DPBDE; (b) (+)-anti-DPBDE; (c) (-)-syn-DPBDE; (d) (+)-syn-DPBDE; (e) trans-derivative of (-)-anti-DBPDE; (f) cis-derivative of (-)-anti-DBPDE; (g) transderivative of (+)-syn-DBPDE; (h) cis-derivative of (+)-syn-DBPDE.

Table 1. Molecular docking studies of diastereomers of DBPDEs with DNA.

\begin{tabular}{c|c|c}
\multicolumn{2}{c|}{ Compounds } & DNA \\
\hline (-)-anti-DBPDE & $\mathrm{BE}^{\#}(\mathrm{kcal} / \mathrm{mol})$ & $\mathrm{Ki} *(\mu \mathrm{M})$ \\
\hline (-)-trans-anti- & -8.49 & 0.599 \\
\hline DBPDE & -9.83 & 0.062 \\
\hline DBPDE $(-)$-cis-anti- & & 0.308 \\
\hline (+)-anti-DBPDE & -8.88 & 3.21 \\
\hline (-)-syn-DBPDE & & 5.24 \\
\hline (+)-syn-DBPDE & -7.50 & 0.612 \\
\hline DBPDE $(+)$-trans-syn- & -7.20 & 0.069 \\
\hline DBPDE & -8.48 & 0.479
\end{tabular}

${ }^{\#}$ Calculated free energy of binding $(\Delta \mathrm{G})$ in $\mathrm{kcal} / \mathrm{mol}$.

"Calculated inhibition constant Ki from AutoDock Tools 4.0.

Furthermore, dC1, dC2, dA3, dT4, dG6, dC7, dG16, dC17, dG18, dA19, dT20, and dG21 of DNA are involved in molecular interaction with $( \pm)$-anti-DBPDE, $( \pm)$-syn-DBPDE, trans- and cis- form of (-)-anti-DBPDE and (+)-syn-DBPDE. H-bonds were formed by dT20 
with ( \pm -)-anti-DBPDE and (-)-syn-DBPDE, dG6 with (+)-syn-DBPDE, dC2, dT4, dA3 $\left(\mathrm{N}^{6}\right)$ with (-)-trans-anti-DBPDE, dT4, dT20, dA19 $\left(\mathrm{N}^{6}, \mathrm{~N}^{7}\right)$ with (-)-cis-anti-DBPDE, dT4, dA19 $\left(\mathrm{N}^{6}, \mathrm{~N}^{7}\right)$, dT20 with (+)-trans-syn-DBPDE, dA19 $\left(\mathrm{N}^{6}, \mathrm{~N}^{7}\right)$ and dT20 with (+)-cis-syn-DBPDE (Figure 2a-h). The binding pattern of different DBPDEs with DNA were followed the order as (-)-trans-anti-DBPDE > (+)-trans-syn-DBPDE > (-)-cis-anti-DBPDE > (+)-cis-syn-DBPDE > $(-)$-anti-DBPDE $>(+)$-syn-DBPDE $>(+)$-anti-DBPDE $>(-)$-syn-DBPDE (Table 1$)$.

In addition, docking simulation was also carried out in order to assess the binding activity of ( \pm -anti-DBPDE and ( \pm )-syn-DBPDE with individual nucleotides, dA, dG, dC and dT. Almost similar interactions were observed by all diol-epoxides (DEs) of DBP as highlighted by their binding energies ranging from -4.12 to $-4.92 \mathrm{kcal} / \mathrm{mol}$. On the basis of $\mathrm{Ki}$ values, the order of activity of (-)-anti-DBPDE and (-)-syn-DBPDE towards individual nucleotides were observed the same and followed the order as- $\mathrm{dG}>\mathrm{dT}>\mathrm{dA}>\mathrm{dC}$. Furthermore, the order of activity of (+)-anti-DBPDE (dT $>\mathrm{dC}>\mathrm{dA}>\mathrm{dG})$ and (+)-synDBPDE $(\mathrm{dT}>\mathrm{dG}>\mathrm{dC}>\mathrm{dA}$ ) were observed different as compared to (-)-anti-DBPDE and (-)-syn-DBPDE (Table 2).

Table 2. Molecular docking studies of ( \pm )-anti- and -syn-DBPDEs with individual nucleotides.

\begin{tabular}{l|l|l|l|l|l|l|l|l} 
Compounds & \multicolumn{2}{l}{ dA } & \multicolumn{1}{l}{ dG } & \multicolumn{2}{l}{ dC } & \multicolumn{2}{l}{ dT } \\
\hline & $\begin{array}{l}\mathrm{BE} \\
(\mathrm{kcal} / \mathrm{mol})\end{array}$ & $\begin{array}{l}\mathrm{Ki}^{*} \\
(\mu \mathrm{M})\end{array}$ & $\mathrm{BE}(\mathrm{kcal} / \mathrm{mol})$ & $\begin{array}{l}\mathrm{Ki} \\
(\mu \mathrm{M})\end{array}$ & $\mathrm{BE}(\mathrm{kcal} / \mathrm{mol})$ & $\begin{array}{l}\mathrm{Ki} \\
(\mu \mathrm{M})\end{array}$ & $\mathrm{BE}(\mathrm{kcal} / \mathrm{mol})$ & $\begin{array}{l}\mathrm{Ki} \\
(\mu \mathrm{M})\end{array}$ \\
\hline (-)-anti-DBPDE & -4.53 & 477.41 & -4.64 & 398.48 & -4.27 & 743.52 & -4.64 & 399.59 \\
\hline (+)-anti-DBPDE & -4.32 & 613.07 & -4.12 & 845.27 & -4.70 & 365.50 & -4.83 & 263.15 \\
\hline (-)-syn-DBPDE & -4.55 & 466.01 & -4.73 & 343.86 & -4.27 & 740.21 & -4.61 & 420.21 \\
\hline (+)-syn-DBPDE & -4.48 & 548.80 & -4.61 & 418.81 & -4.56 & 444.92 & -4.92 & 224.38
\end{tabular}

"Calculated free energy of binding $(\Delta \mathrm{G})$ in $\mathrm{kcal} / \mathrm{mol}$.

*Calculated inhibition constant Ki from AutoDock Tools 4.0.

Our comprehensive in silico investigation observed that no $\mathrm{N}^{6}-\mathrm{dA}$ adduct was formed either in ( \pm )-anti-DBPDE or $( \pm)$-syn-DBPDE. However, dT and dG adduct formed with diolepoxides described above, contrary to the wet lab data. Moreover, promising results were found when cis- and trans-conformations of most carcinogenic diol-epoxides of DBP, (-)-antiDBPDE, and (+)-syn-DBPDE were taken under consideration. In our docking experiment, $\mathrm{N}^{6}$ dA adduct with (-)-trans-anti-DBPDE, $\mathrm{N}^{6}, \mathrm{~N}^{7}$-dA adduct with (-)-cis-anti-DBPDE, (+)-transsyn-DBPDE and (+)-cis-syn-DBPDE (Figure 2e-h) were formed which is completely consistent to the reported data [45]. Furthermore, weak interactions of $( \pm)$-anti-DBPDE and $( \pm$ )-syn-DBPDE with individual nucleotides, $\mathrm{dA}, \mathrm{dG}, \mathrm{dC}$, and $\mathrm{dT}$ compared to DNA emphasized the formation of preferable DNA adduct than individual nucleotides.

\subsection{Molecular interaction studies of diol-epoxides of DBP with NER-proteins.}

Binding pattern of (-)-anti-DBPDE with different proteins were highlighted as- RPA (BE: $-6.01 \mathrm{kcal} / \mathrm{mol}, \mathrm{Ki}: 39.61 \mu \mathrm{M})>\mathrm{XPA}(-5.84 \mathrm{kcal} / \mathrm{mol}, 52.53 \mu \mathrm{M})>\mathrm{hHR} 23 \mathrm{~B}(-5.83$ $\mathrm{kcal} / \mathrm{mol}, 52.85 \mu \mathrm{M})>\operatorname{RFIIH}(-5.61 \mathrm{kcal} / \mathrm{mol}, 77.73 \mu \mathrm{M})>\mathrm{DDB}(-5.54 \mathrm{kcal} / \mathrm{mol}, 86.75 \mu \mathrm{M})>$ DPOL $\varepsilon(-5.50 \mathrm{kcal} / \mathrm{mol}, 92.25 \mu \mathrm{M})>\mathrm{XPC}(-5.48 \mathrm{kcal} / \mathrm{mol}, 96.94 \mu \mathrm{M})>\mathrm{DPOL} \delta(-5.38$ $\mathrm{kcal} / \mathrm{mol}, 114.08 \mu \mathrm{M})>\mathrm{PCNA}(-5.21 \mathrm{kcal} / \mathrm{mol}, 151.74 \mu \mathrm{M})>\mathrm{XPF}(-4.85 \mathrm{kcal} / \mathrm{mol}, 280.08 \mu \mathrm{M})$ (Table 3). PHE1076, ASN950, ASN952, PRO951, TRP953, ARG1080, LYS1081 residues of DDB, LEU90, LYS30, GLU27, THR26, LEU25, GLU24 residues of XPC, GLN63,PRO61, GLN23, VAL62, GLN20 residues of hHR23B, ASP23, THR74, ASN76, THR75, PHE27, HIS45, ILE43, GLN17 residues of TFIIH, LYS70, PHE24, HIS23, PRO73, LYS71, ILE68, 
VAL69 residues of XPA, GLU407, PHE300, GLU299, PRO296, THR297, ILE405 residues of RPA, MET884, THR892, PHE889, ILE890, ALA866 residues of XPF, LEU144, VAL150, SER151, ASP149,ILE148, GLY146, THR147 residues of DPOL $\delta$, LYS163, LEU229, LYS213, TYR52, PRO232 residues of DPOL $\varepsilon$, GLU124, VAL123, ILE128, ASN36, GLN49,GLN38, LEU37 and GLN125 residues of PCNA were engaged in hydrophobic interactions with (-)-anti-DBPDE (Figure $3 \mathrm{a}-\mathrm{j}$ ).

Table 3. Molecular docking studies of $( \pm)$-anti- and -syn-DBPDEs with NER proteins.

\begin{tabular}{|c|c|c|c|c|c|c|c|c|}
\hline \multirow[t]{2}{*}{ Proteins } & \multicolumn{2}{|c|}{ (-)-anti-DBPDE } & \multicolumn{2}{|c|}{ (+)-anti-DBPDE } & \multicolumn{2}{|c|}{ (-)-syn-DBPDE } & \multicolumn{2}{|c|}{ (+)-syn-DBPDE } \\
\hline & $\begin{array}{l}\mathrm{BE}^{\#} \\
(\mathrm{kcal} / \mathrm{mol})\end{array}$ & $\begin{array}{l}\mathrm{Ki}^{*} \\
(\mu \mathrm{M})\end{array}$ & $\mathrm{BE}(\mathrm{kcal} / \mathrm{mol})$ & $\begin{array}{l}\mathrm{Ki} \\
(\mu \mathrm{M})\end{array}$ & $\mathrm{BE}(\mathrm{kcal} / \mathrm{mol})$ & $\begin{array}{l}\mathrm{Ki} \\
(\mu \mathrm{M})\end{array}$ & $\mathrm{BE}(\mathrm{kcal} / \mathrm{mol})$ & $\begin{array}{l}\mathrm{Ki} \\
(\mu \mathrm{M})\end{array}$ \\
\hline DDB & -5.54 & 86.75 & -5.14 & 169.79 & -6.10 & 33.73 & -5.33 & 124.41 \\
\hline XPC & -5.48 & 96.94 & -5.77 & 58.74 & -5.76 & 59.98 & -6.51 & 16.95 \\
\hline hHR23B & -5.83 & 52.85 & -5.50 & 93.17 & -5.21 & 151.74 & -5.76 & 60.13 \\
\hline TFIIH & -5.61 & 77.73 & -5.69 & 66.95 & -5.24 & 144.17 & -6.05 & 36.91 \\
\hline XPA & -5.84 & 52.53 & -4.89 & 261.53 & -5.99 & 40.40 & -6.19 & 28.89 \\
\hline RPA & -6.01 & 39.61 & -5.57 & 82.06 & -6.50 & 17.28 & -6.51 & 16.84 \\
\hline XPF & -4.85 & 280.08 & -5.12 & 177.81 & -6.54 & 16.02 & -6.22 & 27.61 \\
\hline DPOL $\delta$ & -5.38 & 114.08 & -5.18 & 160.57 & -5.59 & 80.34 & -5.37 & 115.10 \\
\hline DPOL $\varepsilon$ & -5.50 & 92.25 & -5.92 & 45.47 & -5.11 & 179.12 & -6.21 & 28.07 \\
\hline PCNA & -5.21 & 151.74 & -5.61 & 76.91 & -6.52 & 16.57 & -6.57 & 15.37 \\
\hline
\end{tabular}

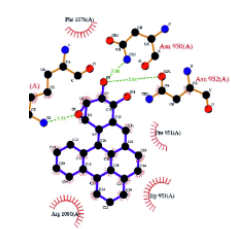

(a)

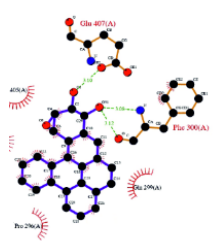

(f)

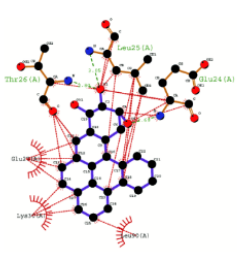

(b)

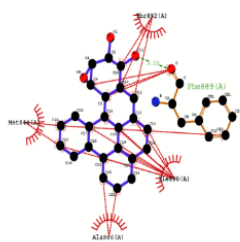

(g)

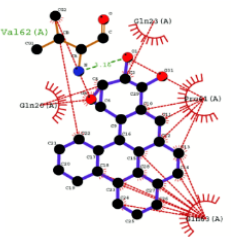

(c)

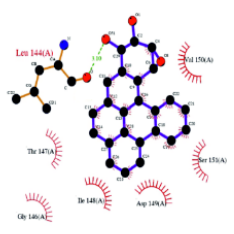

(h)

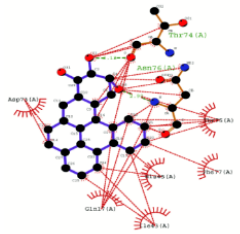

(d)

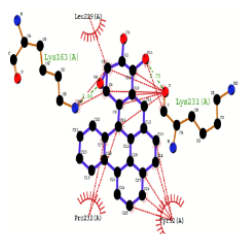

(i)

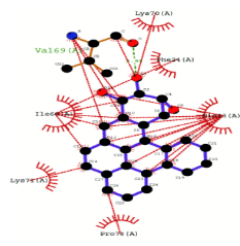

(e)

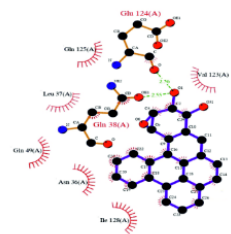

(j)

Figure 3. Molecular interactions of (-)-anti-DBPDE with (a) DDB; (b) XPC; (c) hHR23B; (d) TFIIH; (e) XPA; (f) RPA; (g) XPF; (h) DPOL $\delta$; (i) DPOL $\varepsilon$; (j) PCNA.

Moreover, binding pattern of (+)-syn-DBPDE with different proteins were followed the order as- PCNA $(-6.57 \mathrm{kcal} / \mathrm{mol}, 15.37 \mu \mathrm{M})>\mathrm{RPA}(-6.51 \mathrm{kcal} / \mathrm{mol}, 16.84 \mu \mathrm{M})>\mathrm{XPC}(-6.51$ $\mathrm{kcal} / \mathrm{mol}, 16.95 \mu \mathrm{M})>\mathrm{XPF}(-6.22 \mathrm{kcal} / \mathrm{mol}, 27.61 \mu \mathrm{M})>$ DPOL $\varepsilon(-6.21 \mathrm{kcal} / \mathrm{mol}, 28.07 \mu \mathrm{M})>$ XPA $(-6.19 \mathrm{kcal} / \mathrm{mol}, 28.89 \mu \mathrm{M})>\mathrm{TFIIH}(-6.05 \mathrm{kcal} / \mathrm{mol}, 36.91 \mu \mathrm{M})>\mathrm{hHR} 23 \mathrm{~B}(-5.76$ $\mathrm{kcal} / \mathrm{mol}, 60.13 \mu \mathrm{M})>$ DPOL $\delta(-5.37 \mathrm{kcal} / \mathrm{mol}, 115.0 \mu \mathrm{M})>$ DDB $(-5.33 \mathrm{kcal} / \mathrm{mol}, 124.41$ $\mu \mathrm{M}$ ) (Table 3). GLN1055, SER1075, LEU1052, ALA1085, PRO1084, SER1071, PHE1088, PHE998 residues of DDB, ARG58, LYS54, LYS66, ILE69, ILE73, LYS51 residues of XPC, GLY1, GLU7, PHE8, LEU6, PRO5, HIS50, GLN, residues of hHR23B, LYS18, ASN46, GLN17, LYS19, ASP73, THR74, GLY27 residues of TFIIH, LEU65, LEU58, GLU62, 
PRO63, PHE67, TYR84 residues of XPA, GLU407, PHE302, PHE300, ILE405, GLN299, PRO406 residues of RPA, ARG853, LYS850, HIS858, LEU877, ILE876, SER854, HIS857 residues of XPF, GLY411, LEU362, THR407, PRO408, HIS361, GLU359, ASP360, PHE410 residues of DPOL $\delta$, ASN359, GLU101, ASP358, ARG93, VAL97,MET100, LEU315, GLN314, ARG111 residues of DPOL $\varepsilon$, ASP29, GLN38, VAL123,LEU126, GLY127, ILE128 and GLN49 residues of PCNA were involved in hydrophobic interactions with (+)-synDBPDE (Figure 4a-j). Further, almost similar results were obtained with (+)-anti-DBPDE and (-)-syn-DBPDE showing binding energy in the range of -4.89 to $-6.54 \mathrm{kcal} / \mathrm{mol}$ and $\mathrm{Ki}$ value in the range of 16.02 to $261.53 \mu \mathrm{M}$ (Table 3).

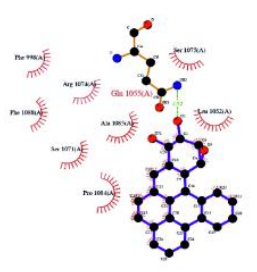

(a)

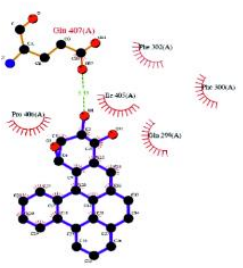

(f)

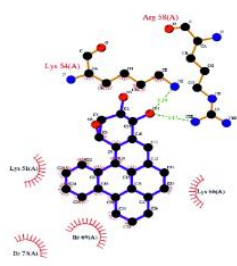

(b)

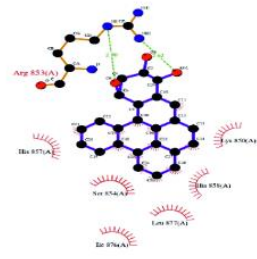

(g)

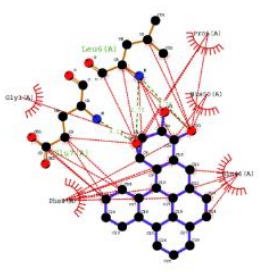

(c)

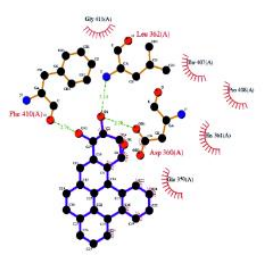

(h)

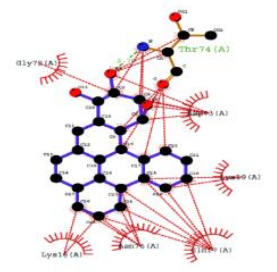

(d)

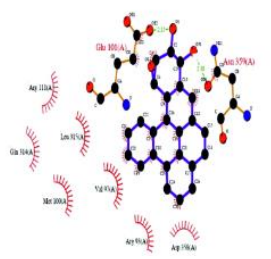

(i)

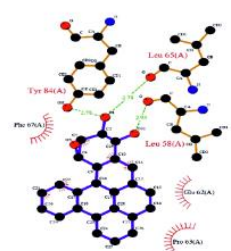

(e)

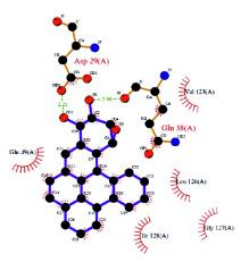

(j)

Figure 4. Molecular interactions of (+)-syn-DBPDE with (a) DDB; (b) XPC; (c) hHR23B; (d) TFIIH; (e) XPA; (f) RPA; (g) XPF; (h) DPOL $\delta$; (i) DPOL $\varepsilon$; (j) PCNA.

The diol-epoxides of DBP, either ( \pm )-anti-DBPDE or $( \pm)$-syn-DBPDE do not interact with $\mathrm{N}^{6}$-dA of DNA; however, it interacted more preferably with dT and dG of DNA. However, when cis- and trans-conformations of most potent carcinogenic diol-epoxides of DBP, namely (-)-anti-DBPDE and (+)-syn-DBPDE were taken under consideration, also obtained similar results. Cis- and trans-refer to the relative orientation of the dA's amino group or dG bound to the benzylic carbon and the adjacent hydroxyl group. Cis adducts are less conformationally flexible than trans adducts because they are inherently more sterically crowded with two hydroxyl groups located on the same side of the benzylic ring as the purine and sugar-residues. In contrast, the two hydroxyl groups in the trans- adducts are located on the opposite side of the purine and sugar-residues, leading to a less crowded adduct [13]. As a result, some of these stereoisomeric adducts may adopt different conformations in DNA. Diol-epoxide DNA adducts can be relative to the DNA helix, either intercalated or external, and situated in the major or minor groove, all depending on the adduct's stereochemistry (trans or cis) and base preferences ( $\mathrm{dA}$ or $\mathrm{dG}$ ). This disturbs the DNA conformation to a varying extent leading to a more or less efficient recognition and subsequent removal by the DNA repair machinery [19, 48-52]. In our in silico experiment, $\mathrm{N}^{6}$-dA adduct with trans-derivative of (-)-anti-DBPDE, $\mathrm{N}^{6}$, $\mathrm{N}^{7}$-dA adduct with cis-derivative (-)-anti-DBPDE, trans-derivative of (+)-syn-DBPDE and cisderivative of (+)-syn-DBPDE were formed, which is in agreement to wet lab findings [45]. 


\subsection{Validation of docking methodology.}

Re-docking of ligand truncated from the complex (PDB: 2LZK) exhibited the same binding orientation as in the parent molecule. Similar binding of the re-docked ligand into the binding cavity of protein ascertained the accuracy of the binding and docking parameters used in the study (Figure 5).

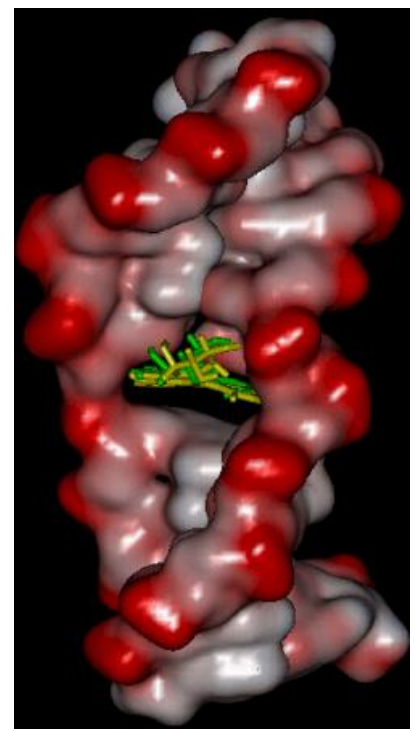

Figure 5. Validation of docking methodology showing the same binding orientation of the ligand present within the DNA (green) and re-docking the same (yellow).

\section{Conclusions}

The biological functions of numerous bioactive molecules are closely dependent on specific molecular interactions of integrated cellular pathways. Thus, understanding these interactions helps advance the existing knowledge to correct the imbalances of integrated pathways. The equilibrium between DNA adducts formation and its repair or removal by the NER pathway is essentially required to maintain perfect cellular homeostasis. Our results based on the molecular docking investigated that the preferential binding tendencies of DBPDEs towards DNA are more than that of proteins of NER pathways as exhibited by $\Delta \mathrm{G}$ and $\mathrm{Ki}$ values. Stronger interactions of (-)-anti-DBPDE and (+)-syn-DBPDE with DNA further favor forming more stable adducts than their removal or repair, which may subsequently lead to mutation and cancer. These findings may enhance our knowledge of the most carcinogenic naturally occurring PAH-DNA interactions to design new or test the existing molecules for the prevention and therapeutics of DBP-induced cancers.

\section{Funding}

This research received no external funding.

\section{Acknowledgments}

This work was supported by Integral University, Lucknow, India.

\section{Conflicts of Interest}

The authors declare no conflict of interest. 


\section{References}

1. Guttenplan, J.B.; Chen, K.-M.; Sun, Y.-W.; Shalaby, N.A.E.; Kosinska, W.; Desai, D.; Gowda, K.; Amin, S.; El-Bayoumy, K. Effects of the Tobacco Carcinogens N'-Nitrosonornicotine and Dibenzo[a,l]pyrene Individually and in Combination on DNA Damage in Human Oral Leukoplakia and on Mutagenicity and Mutation Profiles in lacI Mouse Tongue. Chem. Res. Toxicol. 2019, 32, 1893-1899, https://doi.org/10.1021/acs.chemrestox.9b00257.

2. Rastegari Mehr, M.; Keshavarzi, B.; Moore, F.; Fooladivanda, S.; Sorooshian, A.; Biester, H. Spatial distribution, environmental risk and sources of heavy metals and polycyclic aromatic hydrocarbons (PAHs) in surface sediments-northwest of Persian Gulf. Cont. Shelf Res. 2020, 193, 104036, https://doi.org/10.1016/j.csr.2019.104036.

3. Thiäner, J.B.; Nett, L.; Zhou, S.; Preibisch, Y.; Hollert, H.; Achten, C. Identification of 7-9 ring polycyclic aromatic hydrocarbons in coals and petrol coke using High performance liquid chromatography - Diode array detection coupled to Atmospheric pressure laser ionization - Mass spectrometry (HPLC-DAD-APLI-MS), Environ. Pollut. 2019, 252, 723-732, https://doi.org/10.1016/j.envpol.2019.05.109.

4. Hindersmann, B.; Achten, C. Urban soils impacted by tailings from coal mining: PAH source identification by 59 PAHs, BPCA and alkylated PAHs. Environ. Pollut. 2018, 242, 1217-1225, https://doi.org/10.1016/j.envpol.2018.08.014.

5. Sibeko, M.A.; Adeniji, A.O.; Okoh, O.O.; Hlangothi, S.P. Trends in the management of waste tyres and recent experimental approaches in the analysis of polycyclic aromatic hydrocarbons (PAHs) from rubber crumbs. Environmental Science and Pollution Research 2020, https://doi.org/10.1007/s11356-020-09703-2.

6. Barnes, J.L.; Zubair, M.; John, K.; Poirier, M.C.; Martin, F.L. Carcinogens and DNA damage. Biochem. Soc. Trans. 2018, 46, 1213-1224, https://doi.org/10.1042/BST20180519.

7. Hwa Yun, B.; Guo, J.; Bellamri, M.; Turesky, R.J. DNA adducts: Formation, biological effects, and new biospecimens for mass spectrometric measurements in humans. Mass Spectrom. Rev. 2020, 39, 55-82, https://doi.org/10.1002/mas.21570.

8. Ma, B.; Stepanov, I.; Hecht, S.S. Recent studies on DNA adducts resulting from human exposure to tobacco smoke. Toxics 2019, 7, 16, https://doi.org/10.3390/toxics7010016.

9. Khan, M.K.A.; Akhtar, S.; Arif, J.M. Development of In Silico Protocols to Predict Structural Insights into the Metabolic Activation Pathways of Xenobiotics. Interdisciplinary Sciences: Computational Life Sciences 2018, 10, 329-345, https://doi.org/10.1007/s12539-017-0237-4.

10. Makarska-Bialokoz, M. Comparative study of binding interactions between porphyrin systems and aromatic compounds of biological importance by multiple spectroscopic techniques: A review. Spectrochimica Acta Part A: Molecular and Biomolecular Spectroscopy 2018, 200, 263-274, https://doi.org/10.1016/j.saa.2018.04.037.

11. Ewa, B.; Danuta, M.-ŠS. Polycyclic aromatic hydrocarbons and PAH-related DNA adducts. J. Appl. Genet. 2017, 58, 321-330, https://doi.org/10.1007/s13353-016-0380-3.

12. Poirier, M.C.; Beland, F.A.; Divi, K.V.; Damon, A.L.; Ali, M.; Vanlandingham, M.M.; Churchwell, M.I.; Von Tungeln, L.S.; Dwyer, J.E.; Divi, R.L.; Beauchamp, G.; Martineau, D. In vivo localization and postmortem stability of benzo[a]pyrene-DNA adducts. Environ. Mol. Mutag. 2020, 61, 216-223, https://doi.org/10.1002/em.22337.

13. Bourgart, E.; Barbeau, D.; Marques, M.; von Koschembahr, A.; Béal, D.; Persoons, R.; Leccia, M.-T.; Douki, T.; Maitre, A. A realistic human skin model to study benzo[a]pyrene cutaneous absorption in order to determine the most relevant biomarker for carcinogenic exposure. Arch. Toxicol. 2019, 93, 81-93, https://doi.org/10.1007/s00204-018-2329-2.

14. Wang, P.; Chen, Y.; Wang, L.; Wu, Y.; Wang, L.; Wu, Y.; Gong, Z. The intervention mechanism of folic acid for benzo (a) pyrene toxic effects in vitro and in vivo. Eur. J. Cancer Prev. 2019, 28, 355, https://doi.org/10.1097/CEJ.0000000000000461.

15. Shiizaki, K.; Kawanishi, M.; Yagi, T. Modulation of benzo[a]pyrene-DNA adduct formation by CYP1 inducer and inhibitor. Genes and Environment 2017, 39, 14, https://doi.org/10.1186/s41021-017-0076-X.

16. Li, W.; Hu, J.; Adebali, O.; Adar, S.; Yang, Y.; Chiou, Y.-Y.; Sancar, A. Human genome-wide repair map of DNA damage caused by the cigarette smoke carcinogen benzo[a]pyrene. Proceedings of the National Academy of Sciences 2017, 114, 6752, https://doi.org/10.1073/pnas.1706021114.

17. Amente, S.; Di Palo, G.; Scala, G.; Castrignanò, T.; Gorini, F.; Cocozza, S.; Moresano, A.; Pucci, P.; Ma, B.; Stepanov, I.; Lania, L.; Pelicci, P.G.; Dellino, G.I.; Majello, B. Genome-wide mapping of 8-oxo-7,8-dihydro2'-deoxyguanosine reveals accumulation of oxidatively-generated damage at DNA replication origins within transcribed long genes of mammalian cells. Nucleic Acids Res. 2019, 47, 221-236, https://doi.org/10.1093/nar/gky1152.

18. Chen, K.-M.; Sun, Y.-W.; Kawasawa, Y.I.; Salzberg, A.C.; Zhu, J.; Gowda, K.; Aliaga, C.; Amin, S.; Atkins, H.; El-Bayoumy, K. Black Raspberry Inhibits Oral Tumors in Mice Treated with the Tobacco Smoke Constituent Dibenzo(def,p)chrysene Via Genetic and Epigenetic Alterations. Cancer Prevention Research 2020, 13, 357, https://doi.org/10.1158/1940-6207.CAPR-19-0496. 
19. Chen, K.-M.; Sun, Y.-W.; Cooper, T.K.; Benitez, G.; Aliaga, C.; Zhu, J.; Gowda, K.; Amin, S.; El-Bayoumy, K. Comparative Tumorigenicity and DNA Damage Induced by Dibenzo[def,p]chrysene and Its Metabolites in the Mouse Ovary. Chem. Res. Toxicol. 2018, 31, 1111-1118, https://doi.org/10.1021/acs.chemrestox.8b00152.

20. Hu, J.; Selby, C.P.; Adar, S.; Adebali, O.; Sancar, A. Molecular mechanisms and genomic maps of DNA excision repair in Escherichia coli and humans. J. Biol. Chem. 2017, 292, 15588-15597, https://doi.org/10.1074/jbc.R117.807453.

21. Kitsera, N.; Rodriguez-Alvarez, M.; Emmert, S.; Carell, T.; Khobta, A. Nucleotide excision repair of abasic DNA lesions. Nucleic Acids Res. 2019, 47, 8537-8547, https://doi.org/10.1093/nar/gkz558.

22. Ait Saada, A.; Lambert, S.A.E.; Carr, A.M. Preserving replication fork integrity and competence via the homologous recombination pathway. DNA Repair 2018, 71, 135-147, https://doi.org/10.1016/j.dnarep.2018.08.017

23. Zghal, M.; Fazaa, B.; Abdelhak, S.; Mokni, M. Xeroderma pigmentosum. Ann. Dermatol. Venereol. 2018, 145, 706-722, https://doi.org/10.1016/j.annder.2018.09.004.

24. Baldauf, K.J.; Salazar-González, R.A.; Doll, M.A.; Pierce Jr, W.M.; States, J.C.; Hein, D.W. Role of Human N-Acetyltransferase 2 Genetic Polymorphism on Aromatic Amine Carcinogen-Induced DNA Damage and Mutagenicity in a Chinese Hamster Ovary Cell Mutation Assay. Environ. Mol. Mutag. 2020, 61, 235-245, https://doi.org/10.1002/em.22331.

25. Stingele, J.; Bellelli, R.; Boulton, S.J. Mechanisms of DNA-protein crosslink repair. Nature Reviews Molecular Cell Biology 2017, 18, 563-573, https://doi.org/10.1038/nrm.2017.56.

26. Tomasova, K.; Cumova, A.; Seborova, K.; Horak, J.; Koucka, K.; Vodickova, L.; Vaclavikova, R.; Vodicka, P. DNA Repair and Ovarian Carcinogenesis: Impact on Risk, Prognosis and Therapy Outcome. Cancers (Basel) 2020, 12, 1713, https://doi.org/10.3390/cancers12071713.

27. Hustedt, N.; Durocher, D. The control of DNA repair by the cell cycle. Nat. Cell Biol. 2017, 19, 1-9, https://doi.org/10.1038/ncb3452.

28. Mu, H.; Geacintov, N.E.; Min, J.-H.; Zhang, Y.; Broyde, S. Nucleotide Excision Repair Lesion-Recognition Protein Rad4 Captures a Pre-Flipped Partner Base in a Benzo[a]pyrene-Derived DNA Lesion: How Structure Impacts the Binding Pathway. Chem. Res. Toxicol. 2017, 30, 1344-1354, https://doi.org/10.1021/acs.chemrestox.7b00074.

29. Guo, S.; Leng, J.; Tan, Y.; Price, N.E.; Wang, Y. Quantification of DNA Lesions Induced by 4(Methylnitrosamino)-1-(3-pyridyl)-1-butanol in Mammalian Cells. Chem. Res. Toxicol. 2019, 32, 708-717, https://doi.org/10.1021/acs.chemrestox.8b00374.

30. Sugasawa, K. Chapter Four - Mechanism and regulation of DNA damage recognition in mammalian nucleotide excision repair. In The Enzymes, Zhao, L., Kaguni, L.S., Eds. Academic Press: 2019; Vol. 45, pp. 99-138, https://doi.org/10.1016/bs.enz.2019.06.004.

31. Yokoi, M.; Hanaoka, F. Two mammalian homologs of yeast Rad23, HR23A and HR23B, as multifunctional proteins. Gene 2017, 597, 1-9, https://doi.org/10.1016/j.gene.2016.10.027.

32. de Oliveira Alves, N.; Martins Pereira, G.; Di Domenico, M.; Costanzo, G.; Benevenuto, S.; de Oliveira Fonoff, A.M.; de Souza Xavier Costa, N.; Ribeiro Júnior, G.; Satoru Kajitani, G.; Cestari Moreno, N.; Fotoran, W.; Iannicelli Torres, J.; de Andrade, J.B.; Matera Veras, M.; Artaxo, P.; Menck, C.F.M.; de Castro Vasconcellos, P.; Saldiva, P. Inflammation response, oxidative stress and DNA damage caused by urban air pollution exposure increase in the lack of DNA repair XPC protein. Environ. Int. 2020, 145, 106150, https://doi.org/10.1016/j.envint.2020.106150.

33. Lee, J.; Hitzenberger, M.; Rieger, M.; Kern, N.R.; Zacharias, M.; Im, W. CHARMM-GUI supports the Amber force fields. The Journal of Chemical Physics 2020, 153, 035103, https://doi.org/10.1063/5.0012280.

34. Li, C.; Sun, J.; Palade, V. Diversity-guided Lamarckian random drift particle swarm optimization for flexible ligand docking. BMC Bioinformatics 2020, 21, 286, https://doi.org/10.1186/s12859-020-03630-2.

35. Sun, J.; Chen, K. NSiteMatch: Prediction of binding sites of nucleotides by identifying the structure similarity of local surface patches. Comput. Math. Methods Med. 2017, 2017, https://doi.org/10.1155/2017/5471607.

36. Neha, S.; Mohammad, F.; Abdulrahman, A.A.; Khan, M.K.A.; Saheem, A.; Salman, A. Design, Sar, and Metabolism Study of Crucifereae Family Compound (Spirobrassinin) and its Analogs for Antiangiogenic $\begin{array}{lllllll}\text { Potential Targeting } \quad \text { Hsp90. } & \text { Curr. } & \text { Proteomics } & \mathbf{2 0 2 0}, & 17, & 1-19 \text {, }\end{array}$ https://doi.org/10.2174/1570164617999200731000719.

37. Khan, M.K.A.; Akhtar, S.; Arif, J.M. Structural Insight into the Mechanism of Dibenzo[a,l]pyrene and Benzo[a]pyrene-Mediated Cell Proliferation Using Molecular Docking Simulations. Interdisciplinary Sciences: Computational Life Sciences 2018, 10, 653-673, https://doi.org/10.1007/s12539-017-0226-7.

38. Álvarez-Carretero, S.; Pavlopoulou, N.; Adams, J.; Gilsenan, J.; Tabernero, L. Vspipe, an integrated resource for virtual screening and hit selection: Applications to protein tyrosine phospahatase inhibition. Molecules 2018, 23, 353, https://doi.org/10.3390/molecules23020353.

39. Zhang, Y.; Forli, S.; Omelchenko, A.; Sanner, M.F. AutoGridFR: Improvements on AutoDock Affinity Maps and Associated Software Tools. J. Comput. Chem. 2019, 40, 2882-2886, https://doi.org/10.1002/jcc.26054. 
40. Saxena, G.; Akhtar, S.; Sharma, N.; Sharma, M.; Siddiqui, M.H.; Khan, M.K.A. Virtual screening, docking and molecular dynamics simulation of selected phytochemical compounds bound to receptor tyrosine kinases: A correlative anti angiogenic study. Bioinformation 2019, 15, 613, https://doi.org/10.6026/97320630015613.

41. Eram, S.; Rajnish, K.; Neha, S.; Salman, A.; Mohd. Kalim Ahmad, K.; Mohtashim, L.; Mohd. Haris, S. Computational Outlook of Marine Compounds as Anti-Cancer Representatives Targeting BCL-2 and Survivin. Curr. Comput. Aided Drug Des. 2019, 15, 265-276, https://doi.org/10.2174/1573409915666190130173138.

42. Syed Sayeed, A.; Salman, A.; Syed Mohd. Danish, R.; Mohammad, A.K.; Usman, S.; Mohd. Kalim, A.K.; Mohd. Haris, S.; Jamal, M.A. Screening and Elucidation of Selected Natural Compounds for AntiAlzheimer's Potential Targeting BACE-1 Enzyme: A Case Computational Study. Curr. Comput. Aided Drug Des. 2017, 13, 311-318, https://doi.org/10.2174/1573409913666170414123825.

43. Sharma, A.; Islam, M.H.; Fatima, N.; Upadhyay, T.K.; Khan, M.K.A.; Dwivedi, U.N.; Sharma, R. Elucidation of marine fungi derived anthraquinones as mycobacterial mycolic acid synthesis inhibitors: an in silico approach. Mol. Biol. Rep. 2019, 46, 1715-1725, https://doi.org/10.1007/s11033-019-04621-0.

44. Khan, F.I.; Lai, D.; Anwer, R.; Azim, I.; Khan, M.K.A. Identifying novel sphingosine kinase 1 inhibitors as therapeutics against breast cancer. J. Enzyme Inhib. Med. Chem. 2020, 35, 172-186, https://doi.org/10.1080/14756366.2019.1692828.

45. Chakraborty, S.; Steinbach, P.J.; Paul, D.; Mu, H.; Broyde, S.; Min, J.-H.; Ansari, A. Enhanced spontaneous DNA twisting/bending fluctuations unveiled by fluorescence lifetime distributions promote mismatch recognition by the Rad4 nucleotide excision repair complex. Nucleic Acids Res. 2018, 46, 1240-1255, https://doi.org/10.1093/nar/gkx1216.

46. Sharma, A.; Islam, M.H.; Fatima, N.; Upadhyay, T.K.; Khan, M.K.A.; Dwivedi, U.N.; Sharma, R. Deciphering the Binding of Natural Terpenoids to Mycobacterium tuberculosis Type III Polyketide Synthase18 (PKS18): An In-Silico Approach. Journal of Applied Pharmaceutical Science 2018, 8, 026-034, https://doi.org/10.7324/JAPS.2018.8504.

47. Akhtar, S.; Khan, M.K.A.; Arif, J.M. Evaluation and Elucidation Studies of Natural Aglycones for Anticancer Potential using Apoptosis-Related Markers: An In silico Study. Interdisciplinary Sciences: Computational Life Sciences 2018, 10, 297-310, https://doi.org/10.1007/s12539-016-0191-6.

48. Kwofie, S.K.; Broni, E.; Teye, J.; Quansah, E.; Issah, I.; Wilson, M.D.; Miller, W.A.; Tiburu, E.K.; Bonney, J.H.K. Pharmacoinformatics-based identification of potential bioactive compounds against Ebola virus protein VP24. Comput. Biol. Med. 2019, 113, 103414, https://doi.org/10.1016/j.compbiomed.2019.103414.

49. Vázquez-Gómez, G.; Rocha-Zavaleta, L.; Rodríguez-Sosa, M.; Petrosyan, P.; Rubio-Lightbourn, J. Benzo[a]Pyrene Activates an AhR/Src/ERK Axis That Contributes to CYP1A1 Induction and Stable DNA Adducts Formation in Lung Cells. Toxicol. Lett. 2018, 289, 54-62. https://doi.org/10.1016/j.toxlet.2018.03.012.

50. Shafirovich, V.; Kolbanovskiy, M.; Kropachev, K.; Liu, Z.; Cai, Y.; Terzidis, M.A.; Masi, A.; Chatgilialoglu, C.; Amin, S.; Dadali, A.; Broyde, S.; Geacintov, N.E. Nucleotide Excision Repair and Impact of Site-Specific 5',8-Cyclopurine and Bulky DNA Lesions on the Physical Properties of Nucleosomes. Biochemistry 2019, 58, 561-574, https://doi.org/10.1021/acs.biochem.8b01066.

51. Schmitt, E.E.; Barhoumi, R.; Metz, R.P.; Porter, W.W. Circadian Regulation of Benzo[a]Pyrene Metabolism and DNA Adduct Formation in Breast Cells and the Mouse Mammary Gland. Mol. Pharmacol. 2017, 91, 178, https://doi.org/10.1124/mol.116.106740.

52. Fahrer, J.; Kaina, B. Impact of DNA repair on the dose-response of colorectal cancer formation induced by dietary carcinogens. Food Chem. Toxicol. 2017, 106, 583-594, https://doi.org/10.1016/j.fct.2016.09.029. 